\title{
Suitability of convective air drying for the production of porous resorcinol- formaldehyde and carbon xerogels
}

Angélique Léonard ${ }^{\mathrm{a},}$, Nathalie Job ${ }^{\mathrm{a}}$, Silvia Blacher ${ }^{\mathrm{a}}$, Jean-Paul Pirard ${ }^{\mathrm{a}}$, Michel Crine ${ }^{\mathrm{a}}$, Wahbi Jomaa $^{\mathrm{b}}$

\footnotetext{
${ }^{a}$ Laboratory of Chemical Engineering, University of Liège, Building B6c - Sart Tilman, B-4000 Liège, Belgium

${ }^{\mathrm{b}}$ TREFLE-ENSAM, Esplanade des Arts et Métiers, F-33405 Talence, France
}

Keywords: A. Carbon xerogels; Porous carbon; C. Transmission electron microscopy; D. Texture.

Production of carbon aerogels by $\mathrm{CO}_{2}$ supercritical drying of resorcinol-formaldehyde (RF) hydrogels followed by pyrolysis in inert atmosphere has been extensively described in the scientific literature, since their introduction by Pekala in 1989 [1]. Supercritical conditions suppress the liquid-vapor interface, avoiding shrinkage and cracking of the material during solvent removal and preserving the porous texture. As supercritical drying remains difficult to apply at an industrial scale because of its expensive and potentially dangerous character, other softer drying techniques have been tested in order to produce an aerogel-like mesoporous texture: freeze-drying [2], vacuum drying [3], microwave drying [4], solvent exchange followed by freeze drying [5] or drying under nitrogen in tube furnace [6],... Quite surprisingly, it appears that conventional convective drying, with controlled air temperature, velocity and humidity, has never been used in order to produce RF xerogels. As this technique is well known and largely used in the industry, it seemed interesting to study its suitability: would this technique enable us to obtain porous RF (and carbon after pyrolysis) xerogels?

Hydrogels have been prepared following the method described by Job et al. [3]. The molar ratio $R / F$ and the dilution ratio $D$, as defined by these latter, were fixed at 0.5 and 5.7 respectively. Three initial values of the $\mathrm{pH}$ of the precursors solution were chosen: 6.6 .5 and $7( \pm 0.05)$. Cylindrical 
samples were obtained by casting $5 \mathrm{ml}$ solution into sealed glass moulds $(\varnothing=22 \mathrm{~mm})$ and putting them for gelation in an oven at $85^{\circ} \mathrm{C}$ during $72 \mathrm{~h}$. After gelation, the samples had a mass comprised between 4.2 and $5.1 \mathrm{~g}$. They have been dried in a classical convective rig, with air at ambient humidity, at a temperature of $70^{\circ} \mathrm{C}$ and a superficial velocity of $2 \mathrm{~m} / \mathrm{s}$, i.e. quite severe drying conditions. Fig. 1a shows the drying curves, i.e. the evolution of mass with time, for the three samples. In each case, mass stabilization occurs after approximately 4 to 5 hours, indicating the end of the drying process. In comparison with vacuum drying, the drying duration is about 40 times shorter [3]. The three samples reached a final mass close to $1.45 \mathrm{~g}$ and kept their monolithic form. Volumetric shrinkage was negligible when $\mathrm{pH}=6$ (orange xerogel), reached $21 \%$ when $\mathrm{pH}=6.5$ (light brown xerogel) and $60 \%$ when $\mathrm{pH}=7$ (dark brown xerogel). At high $\mathrm{pH}$, a large shrinkage is observed even with supercritical drying, because of the 'polymeric' character of the gel [7].
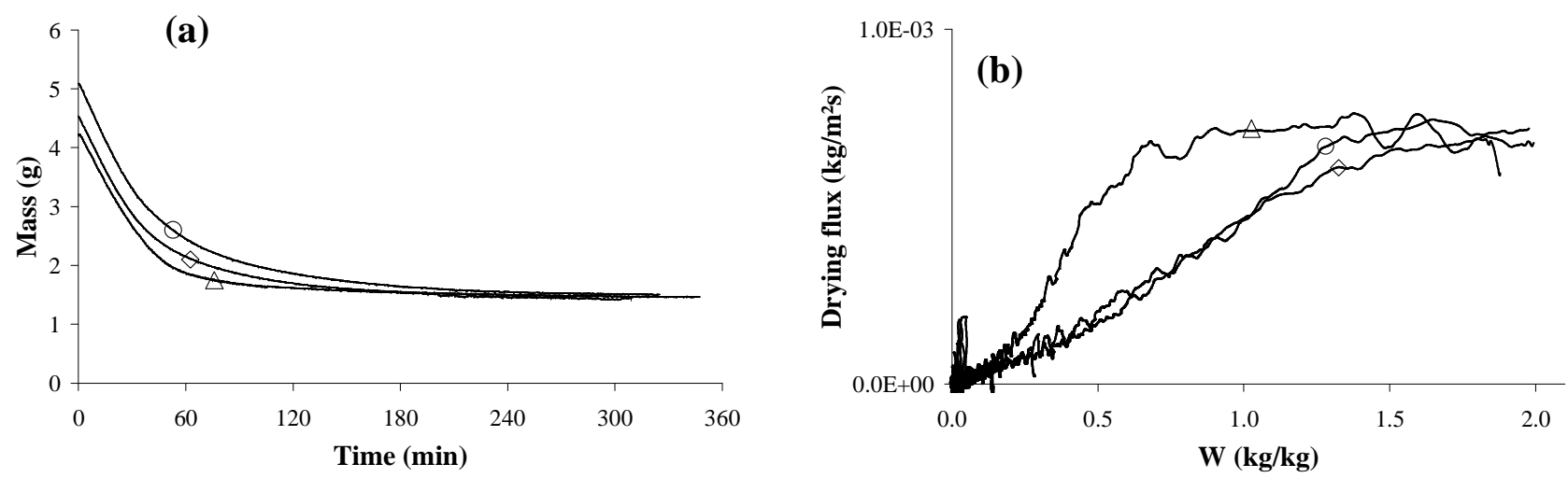

Fig. 1. (a) Drying curves of RF hydrogels: $(\diamond) \mathrm{pH}=6$; (०) $\mathrm{pH}=6.5 ;(\triangle) \mathrm{pH}=7$ and (b) the corresponding drying kinetics $(\diamond) \mathrm{pH}=6 ;(\bigcirc) \mathrm{pH}=6.5 ;(\triangle) \mathrm{pH}=7$.

The drying kinetics are represented in Fig. $1 \mathrm{~b}$ by plotting the drying flux $\left(\mathrm{kg} / \mathrm{m}^{2} \mathrm{~s}\right)$ vs. the water content $W(\mathrm{~kg} / \mathrm{kg})$, expressed on a dry basis, as commonly encountered in the drying literature. A long constant drying phase is observed when $\mathrm{pH}=7$ (up to $\mathrm{W} \cong 0.7 \mathrm{~kg} / \mathrm{kg}$ ), while there is only a continuous decrease of the drying flux when $\mathrm{pH}=6$. A very short constant phase is observed when $\mathrm{pH}=6.5$. This can be related to the shrinkage behavior of the samples: during the constant rate period, the shrinkage is almost ideal, i.e. the volume reduction corresponds exactly to the volume of removed water. The external surface of the sample remains completely wet: external transfer 
limitations prevail. Once shrinkage stops, internal diffusional limitations become predominant. A dried zone progressively develops, from the exterior to the inside of the sample [8].

As high microporous pyrolyzed xerogels are used in many applications, the effect of pyrolysis has been investigated on the gels dried with the proposed method. Pyrolysis has been performed under nitrogen flow in a tubular oven at $800^{\circ} \mathrm{C}$, following the procedure of Job et al. [3]. Transmission electron microscopy (TEM) performed on all samples shows that the xerogels obtained by convective drying present the same structure as Pekala et al. [9] described for supercritical RF xerogels, i.e., a network composed by interconnected particles ("string of pearls") of sizes between 10 and $30 \mathrm{~nm}$ (Fig. 2a). This structure remains after pyrolysis (Fig. 2b) but seems smoother and refined.
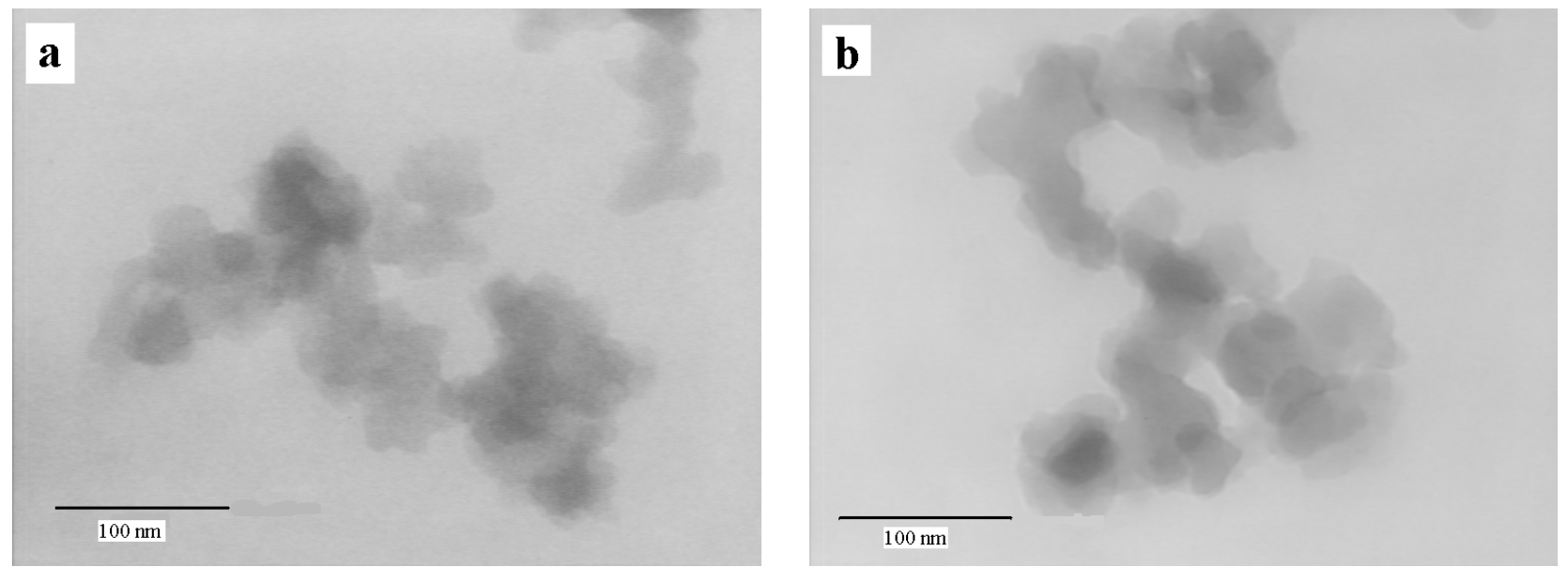

Fig. 2. TEM of gels synthesized with $\mathrm{pH}=7$ before (a) and after (b) pyrolysis.

The textural properties of the samples have been determined before and after pyrolysis by using classical characterization techniques $\left(\mathrm{N}_{2}\right.$ adsorption-desorption isotherms, mercury porosimetry, pycnometry) and calculation methods [10], [11]. Results are summarized in Table 1 where $S_{\mathrm{BET}}$ is the BET specific surface area, $V_{\mathrm{DUB}}$ is the micropores volume calculated by the DubininRadushkevich equation, $V_{\mathrm{p}}$ is the pore volume calculated from the adsorbed volume at saturation, $V_{\mathrm{Hg}}$ is the specific pore volume measured by mercury porosimetry, $V_{\mathrm{v}}$ is the total void volume obtained by combining mercury porosimetry and $\mathrm{N}_{2}$ adsorption results, and $\rho_{\text {bulk }}$ is the apparent density. RF xerogels obtained in the investigated $\mathrm{pH}$ range exhibit specific surfaces and total void 
volumes ranging respectively from 115 to $355 \mathrm{~m}^{2} / \mathrm{g}$ and 0.4 to $2.0 \mathrm{~cm}^{3} / \mathrm{g}$. The corresponding carbon materials develop relatively high specific surfaces $S_{\mathrm{BET}}$ ranging from 430 to $630 \mathrm{~m}^{2} / \mathrm{g}$ and total void volumes $\mathrm{V}_{\mathrm{v}}$ varying from 0.3 to $2.4 \mathrm{~cm}^{3} / \mathrm{g}$. This is similar to results obtained with more sophisticated techniques [2], [3], [12]. It must be pointed out that the apparent density obtained at $\mathrm{pH}=6\left(0.35 \mathrm{~g} / \mathrm{cm}^{3}\right)$ corresponds exactly to the theoretical density when no shrinkage occurs during drying, as observed in this paper.

Table 1

Sample texture characterization

\begin{tabular}{llllllll}
\hline $\mathrm{pH}$ & $\begin{array}{l}S_{\mathrm{BET}} \\
\left(\mathrm{m}^{2} / \mathrm{g}\right)\end{array}$ & $\begin{array}{l}V_{\mathrm{DUB}} \\
\left(\mathrm{cm}^{3} / \mathrm{g}\right)\end{array}$ & $\begin{array}{l}V_{\mathrm{p}} \\
\left(\mathrm{cm}^{3} / \mathrm{g}\right)\end{array}$ & $\begin{array}{l}V_{\mathrm{Hg}} \\
\left(\mathrm{cm}^{3} / \mathrm{g}\right)\end{array}$ & $\begin{array}{l}V_{\mathrm{v}} \\
\left(\mathrm{cm}^{3} / \mathrm{g}\right)\end{array}$ & $\begin{array}{l}\rho_{\text {bulk }} \\
\left(\mathrm{g} / \mathrm{cm}^{3}\right)\end{array}$ & Type of pores \\
\pm 0.05 & \pm 5 & \pm 0.01 & \pm 0.05 & \pm 0.05 & \pm 0.1 & \pm 0.02 & \\
\hline After drying & & & & & & & \\
6 & 115 & 0.06 & 0.65 & 1.95 & 2.0 & 0.35 & Micropores + macropores \\
6.5 & 245 & 0.11 & 1.35 & 1.15 & 1.3 & 0.63 & Micropores + macropores \\
7 & 355 & 0.15 & 0.40 & $-{ }^{\mathrm{a}}$ & 0.4 & 1.05 & Micropores + mesopores \\
\hline After pyrolysis & & & & & & & \\
6 & 630 & 0.27 & 0.80 & 2.00 & 2.4 & 0.39 & Micropores + macropores \\
6.5 & 615 & 0.27 & 1.25 & 1.20 & 1.5 & 0.61 & Micropores + macropores \\
7 & 430 & 0.19 & 0.30 & $-{ }^{\mathrm{a}}$ & 0.3 & 1.34 & Micropores + mesopores \\
\hline
\end{tabular}

${ }^{a}$ Not measured: sample containing micropores and mesopores only and whose pore volume measured at saturation by nitrogen adsorption $\mathrm{V}_{\mathrm{p}}$ corresponds to the total void volume $\mathrm{V}_{\mathrm{v}}$.

These results show that it is possible to produce porous RF and carbon xerogels by using convective drying to remove the solvent, without any preliminary treatment. When synthesis conditions are adequate, the mechanical strength of the gel network is high enough to withstand capillary pressures, avoiding the collapse of the structure. As this technique presents several advantages in comparison with supercritical, vacuum or freeze drying methods (easy industrial implementation, well known, safe and non-expensive process,...), this preliminary research work will go further. The influence of drying conditions (air temperature, velocity and absolute humidity) on the textural properties of the gels is currently investigated, once synthesis conditions have been defined. Detailed mechanical and thermal characterization will also be performed. The change of drying 
conditions but also the investigation of other synthesis conditions should lead to the production of carbon xerogels with higher mesopore volumes, closer to those observed in carbon aerogels.

\section{Acknowledgements}

A. Léonard is grateful to the FNRS (National Fund for Scientific Research, Belgium) for a Postdoctoral Researcher position. Authors thank the Ministère de la Communauté française Belgium (ARC 00/05-265) for its financial support.

\section{References}

[1] Pekala RW. Organic aerogels from the polycondensation of resorcinol with formaldehyde. J Mater Sci 1989; 24:3221-3227.

[2] Mathieu B, Blacher S, Pirard R, Pirard JP, Sahouli B, Brouers F. Freeze-dried resorcinolformaldehyde gels. J Non-Cryst Solids 1997; 212:250-261.

[3] Job N, Pirard R, Marien J, Pirard JP. Porous carbon xerogels with texture tailored by pH control during sol-gel process. Carbon 2004; 42:619-628.

[4] Yamamoto T, Nishimura T, Suzuki T, Tamon H. Effect of drying method on mesoporosity of resorcinol-formaldehyde drygel and carbon gel. Dry Technol 2004; 19:1319-1333.

[5] Yamamoto T, Nishimura T, Suzuki T, Tamon H. Effect of drying conditions on mesoporosity of carbon precursors prepared by sol-gel polycondensation and freeze drying. Carbon 2001; 39:23742376.

[6] Lin C, Ritter JA. Effect of synthesis pH on the structure of carbon xerogels. Carbon 1997; 35:1271-1278.

[7] Pekala RW, Alviso CT, Kong FM, Hulsey SS. Aerogels derived from multifunctional organic monomers. J Non-Cryst Solids 1992; 145:90-98.

[8] Mujumdar AS. Handbook of industrial drying. Second edition. New York: Marcel Dekker, 1995.

[9] Pekala RW. Structure of organic aerogels. 1. Morphology and scaling. Macromolecules 1993; 26:5487-5493. 
[10] Lecloux AJ. Texture of catalysts. In: Anderson JR, Boudart M, editors. Catalysis: Science and Technology vol. 2, Berlin: Springer, 1981: 171.

[11] Pirard R, Alié C, Pirard JP. Specific behaviour of sol-gel materials in mercury porosimetry: collapse and intrusion. Handbook of Sol-Gel Technology, Kluwer, 2004: 211-233.

[12] Horikawa T, Hayashi J, Muroyama K. Size control and characterization of spherical carbon aerogel particles from resorcinol-formaldehyde resin. Carbon 2004; 42:169-175. 